\title{
Thyroxine secretion rate after myocardial infarction
}

\author{
W. A. Harland, J. S. Orr, M. G. Dunnigan, and R. F. C. Sequeira \\ From the Pathology Department, Western Infirmary; Department of Clinical Physics \\ and Bioengineering, 9 West Graham Street; and Stobhill General Hospital, Glasgow
}

Thyroxine secretion rate was measured in 16 patients with acute myocardial infarction. The test was repeated after one week in 5 cases and after three months in 7 cases. No significant difference in thyroxine secretion was found at any time after myocardial infarction compared with a group of patients awaiting operation. This is contrary to the effect of surgery on thyroid function and to the claimed uniformity of metabolic response to injury irrespective of type of trauma.

Injury to tissue is followed not only by local reactions but also by a sequence of general reactions which affect the body as a whole. Born (1970) has claimed that these general reactions constitute a pattern which is very much the same whatever the type of injury, be it trauma, haemorrhage, burning, freezing, or even acute infection. Clearly myocardial infarction can be viewed as a localized tissue trauma and might be expected to cause widespread metabolic effects (Opie, 1971). The well-established alterations in lipid metabolism that occur as early as the second day after myocardial infarction (Fyfe et al., 197I) are probably reactions of this type and it is of interest that similar changes have been reported after surgical trauma (Man et al., 1946). The rises in serum free fatty acid concentration which occur soon after infarction and which have been related to the development of cardiac arrhythmias (Oliver, Kurien, and Greenwood, 1968) are also in this category. Alterations in carbohydrate metabolism, which can persist for months (Sowton, I962), are another important example.

Since reaction to injury involves the whole body, the possibility that the effects have an endocrine basis has to be considered. After acute myocardial infarction, Valori, Thomas, and Shillingford (1967) found increased urinary excretion of both adrenaline and noradrenaline. McDonald et al. (1969) report that the plasma adrenaline concentration is unchanged but that noradrenaline concentration is significantly raised. Siggers, Salter, and Fluck (197I) found that raised plasma levels of adrenaline and noradrenaline after myoReceived 9 March 1972. cardial infarction correlate with raised blood pressure, development of pulmonary oedema, and the return of the patients to the medical wards. Logan and Murdoch (1966) found a significant rise in the plasma hydrocortisone concentration in two-thirds of their patients with myocardial infarction. In some cases the levels were comparable to those found in Cushing's disease. The rise occurred within I2 hours, even preceding the rise of plasma transaminase concentrations. Jacobs and $\mathrm{Na}-$ barro (1969) found raised plasma I I-hydroxycorticosteroid concentrations in myocardial infarction, with the highest levels in patients with severe infarcts. The abnormality persisted for 7 to ro days.

It appears that adrenal response, after injury and myocardial infarction, has attracted most attention while any possible thyroid reaction has been largely neglected. However, there is some evidence to suggest that the thyroid gives a burst of activity in the immediate postoperative state, even after minor operations (Kirby and Johnston, I97I ; Harland, Orr, and Richards, 1972). Furthermore, myocardial infarction is accompanied by a severe emotional stress, and raised proteinbound iodine concentrations have been reported after prolonged emotional stress (Levi, 1967). This paper reports measurement of thyroxine secretion rate in a group of patients with acute myocardial infarction.

\section{Materials and methods}

Thyroxine secretion rate was measured in 15 men and I woman aged from 39 to 75 years who were admitted to a general medical unit with clinical and electrocardiographic evidence of myocardial 
infarction. The diagnosis was confirmed by raised serum transaminase levels in each case. After admission, the severity of the infarction was assessed by the coronary prognostic index as described by Peel et al. (1962); the scores varied from 4 to 23 .

$1 \quad$ The detailed procedures and methods of calculation have been published (Harland et al., 1972). Briefly, each subject was given an intravenous injection of thyroxine labelled with ${ }^{125} I$ or ${ }^{131} I$ and plasma activity was measured for 7 days. Plasma thyroxine concentration was estimated as the protein-bound iodine concentration $\times \mathrm{I} \cdot 53$. The test was started on the day after admission. In 5

- cases a second test was begun after 7 days using a differently labelled radiothyroxine. In 7 cases thyroxine secretion was estimated after 3 or 4 months' convalescence by the simplified procedure of Harland and Orr (I97I).

\section{- Results}

The results are shown in the Table. The single protein-bound iodine value for each patient in the infarct group represents a mean of 3 or 4 measurements. The group mean value was $5.0 \pm \mathrm{I} \cdot 2(\mathrm{SD})$ after infarction and $5.3 \pm \mathrm{I} \cdot 0$ in the convalescent group 3 to 4 months after infarction. No trend either up or down could be discerned throughout the course of the illness.

In every case the plasma activity disappeared at a single exponential rate. The daily fractional disappearance rate was computed by the least squares method, and was $0.119 \pm 0.037$ immediately after infarction and
$0.120 \pm 0.030$ one week after infarction. These disappearance rates are not significantly different either when comparing means or by paired $t$-test $(t=0.179, P=0.43)$. The extrapolated zero time values are also shown. Again, the difference between the immediate and one-week result is not significant.

The thyroxine secretion rate $\left(\mathrm{T}_{4} \mathrm{SR}\right)$ in 16 cases gave a mean value of $105.4 \pm 34.6 \mu \mathrm{g} /$ day immediately after infarction, and 5 of these had a $\mathrm{T}_{4} \mathrm{SR}$ of $91 \cdot 3 \pm 42 \cdot 3 \mu \mathrm{g} /$ day one week later. This difference is not significant (paired $t$-test $t=r \cdot 028, P=0.16)$. During convalescence the $\mathrm{T}_{4} \mathrm{SR}$, measured in 7 survivors, was $108 \cdot 0 \pm 24 \cdot 8 \mu \mathrm{g} /$ day. This is not significantly different from the immediate postinfarction figure $(t=0.542, P=0.30)$. There was no correlation between the severity of the infarct, as judged by the coronary prognostic index, and thyroxine secretion rate $(r=0 \cdot 13)$.

The data in this study provided an indication of the value of our simplified technique for thyroxine secretion rate (Harland and Orr, 1971). Basically this consists of measuring the inverse of the plasma thyroxine specific activity 7 days after an intravenous dose of radiothyroxine. In the $2 \mathrm{r}$ instances for which data were available in this study, the inverse of the plasma specific activity correlated very closely $(\mathrm{r}=0.99)$ with the $\mathrm{T}_{4} \mathrm{SR}$ value calculated by the more extended procedure. The regression coefficient was $5 \cdot 2$, which is slightly greater than the value of 4.6 found previously (Harland and Orr, I97I). This excellent correlation

$\mathrm{TABLE}$ Lists of values for the coronary prognostic index, the plasma protein-bound iodine $(P B I)$ concentration, radiothyroxine turnover data, and the calculated thyroxine secretion rate $\left(T_{4} S R\right)$ immediately after infarction, after $I$ week, and after 3 months' convalescence

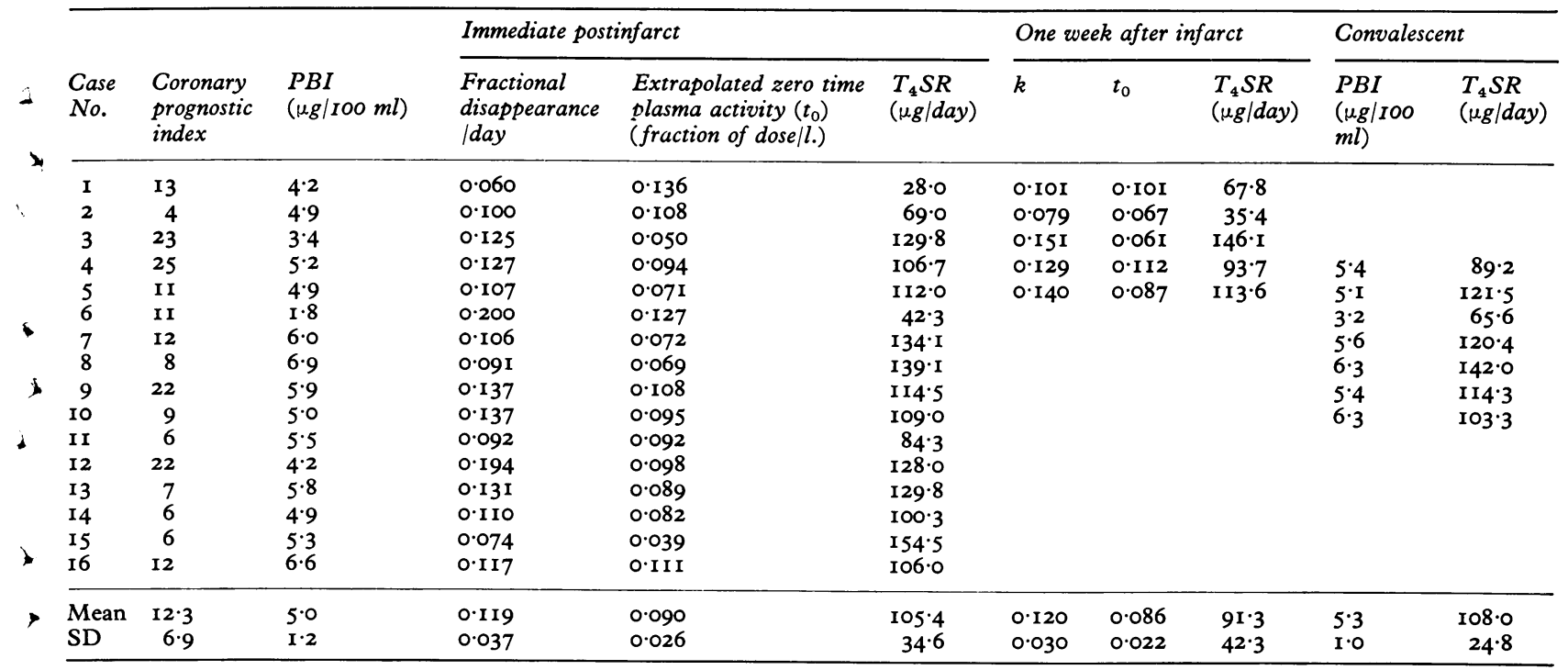


is theoretically to be expected in view of the relatively small scatter of fractional disappearance values around a mean of 0.120 a day.

\section{Discussion}

Myocardial infarction can be regarded as a severe physical and emotional trauma which can elicit a number of metabolic responses. Some of these appear to be mediated by increased activity in both the medulla and cortex of the adrenal gland. Because minor surgery is associated with a burst of thyroid activity (Kirby and Johnston, 197I ; Harland et al., 1972), it seemed reasonable to expect a rise in thyroid activity after myocardial infarction.

Protein-bound iodine concentration can be considered a good indication of the plasma thyroxine concentration, at least at the levels found in these patients (Farran, Haiste, and Hoffenberg, I97I). This concentration was steady throughout the investigation. This is consistent with the observations of Volpé, Vale, and Johnston (1960) who found that the concentration was not significantly affected by the stress of examination, athletic contests, major surgical procedures, or myocardial infarction. However, it is known that the protein-bound iodine concentration can remain unchanged in the face of conspicuously increased thyroxine secretion, as in acute infections (Gregerman and Solomon, 1967) or immediately after surgery (Harland et al., 1972).

The values for the protein-bound iodine, the fractional disappearance rates, and the extrapolated zero time activity values are almost identical with results found in a group of clinically euthyroid individuals from the same population studied by identical methods just before operation (Harland et al., 1972). It is of interest that unlike the myocardial infarction patients, the rate of disappearance of radiothyroxine was increased after operation. This raises the possibility that the increased flow of thyroxine postoperatively is related more to an anaesthetic effect than to the tissue trauma. It may be concluded, however, that the thyroid gland does not respond to myocardial infarction as it does to surgical trauma. This is contrary to the claim that there is a single pattern of response to injury irrespective of the type of trauma (Born, I970).

We wish to thank Mr. T. Randall for skilled technical assistance. The work was supported in part by a financial grant from the Scottish Hospitals Endowment Research Trust.

\section{References}

Born, G. V. R. (1970). Some effects of injury on metabolism. In General Pathology, 4th ed. p. 337. Ed. by $\mathrm{H}$. W. Florey. Lloyd-Luke, London.

Farran, H. E. A., Haiste, C., and Hoffenberg, R. (1971). A comparison of serum PBI and thyroxine iodine levels. Acta Endocrinologica (Kbh.), 68, $45 \mathrm{I}$.

Fyfe, T., Baxter, R. H., Cochran, K. M., and Booth, E. M. (197I). Plasma-lipid changes after myocardial infarction. Lancet, 2, 997.

Gregerman, R. I., and Solomon, N. (1967). Acceleration of thyroxine and triiodothyronine turnover during bacterial pulmonary infections and fever: implications for the functional state of the thyroid during stress and in senescence. Fournal of Clinical Endocrinology and Metabolism, 27, 93.

Harland, W. A., and Orr, J. S. (I97I). A simple clinical method for estimating thyroxine secretion rate. Acta Endocrinologica (Kbh.), 66, I31.

Harland, W. A., Orr, J. S., and Richards, J. R. (1972). Increased thyroxine secretion following surgical operation. Scottish Medical fournal, 17, 92.

Jacobs, H. S., and Nabarro, J. D. N. (1969). Plasma II-hydroxycorticosteroid and growth hormone levels in acute medical illnesses. British Medical fournal, 2, 595.

Kirby, R., and Johnston, I. D. A. (197I). The effect of surgical operation on thyroid activity (abstract). British fournal of Surgery, 58, 305.

Levi, L. (I967). Das experiment am menschen in der psychomatik. Verhandlungen der Deutschen Gesellschaft für innere Medizin, 73, 58.

Logan, R. W., and Murdoch, W. R. (1966). Bloodlevels of hydrocortisone, transaminases, and cholesterol after myocardial infarction. Lancet, 2, 521 .

McDonald, L., Baker, C., Bray, C., McDonald, A., and Restieux, N. (1969). Plasma-catecholamines after cardiac infarction. Lancet, 2, 1021.

Man, E. B., Bettcher, P. G., Cameron, C. M., and Peters, J. P. (1946). Plasma a-amino acid nitrogen and serum lipids of surgical patients. Fournal of Clinical Investigation, 25, 701.

Oliver, M. F., Kurien, V. A., and Greenwood, T. W. (1968). Relation between serum-free-fatty-acids, and arrhythmias and death after acute myocardial infarction. Lancet, 1, 710.

Opie, L. H. (1971). Acute metabolic response in myocardial infarction. British Heart fournal, 33, Suppl., 129.

Peel, A. A. F., Semple, T., Wang, I., Lancaster, W. M., and Dall, J. L. G. (1962). A coronary prognostic index for grading the severity of infarction. British Heart fournal, 24, 745 .

Siggers, D. C., Salter, C., and Fluck, D. C. (1971). Serial plasma adrenaline and noradrenaline levels in myocardial infarction using a new double isotope technique. British Heart fournal, 33, 878.

Sowton, E. (1962). Cardiac infarction and the glucosetolerance test. British Medical fournal, $\mathbf{1}, 84$.

Valori, C., Thomas, M., and Shillingford, J. P. (I967). Urinary excretion of free noradrenaline and adrenaline following acute myocardial infarction. Lancet, r, 127.

Volpé, R., Vale, J., and Johnston, M. W. (1960). The effects of certain physical and emotional tensions and strains on fluctuations in the level of serum protein-bound iodine. Fournal of Clinical Endocrinology and Metabolism, 20, 4I5.

Requests for reprints to Dr. W. A. Harland, Pathology Department, Western Infirmary, Glasgow, GI I 6NT. 